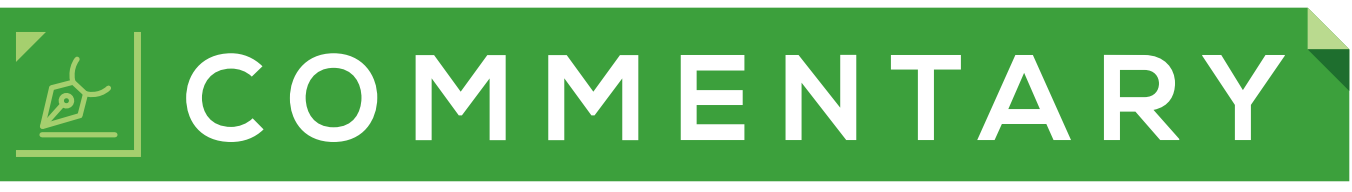

\title{
Librarians' Experiences with Social Media and COVID-19 Misinformation
}

\author{
Authors_Kacy J. Lovelace (kacy.lovelace@marshall.edu), Sabrina Thomas \\ (tho4@marshall.edu), and Lindsey M. Harper (harper166@marshall.edu), \\ University Libraries, Marshall University
}

This article explores our personal experiences with combating misinformation and disinformation about COVID-19 via social media platforms. Next, we describe how sharing our experiences with one another led to the motivation of the current study. Then, we describe the methodology of the present study and examine some of the preliminary results and analysis. Finally, we explore strategies and best practices to mitigate burnout associated with combating COVID-19 misinformation.

\section{Personal Experiences \\ Kacy J. Lovelace}

I use social media to connect with friends, family, and coworkers, and my use increased as I attempted to maintain the normal level of human contact that I was accustomed to as a teaching librarian. What I didn't realize, but probably should have, is that with so many people staying at home - many of them confused, unsure of what was happening in the world, and unsure of where to find credible information - the saturation of mis- and disinformation on my social media news feeds quickly reached an uncomfortable level. Attempting to explain the information creation process, how to analyze resource credibility, and how to find experts sharing trustworthy information began to feel like a second job with no reward. Occasionally, I felt like I was breaching the information divide, but more often than not, I felt that I was sending my knowledge, time, and resources out into the void with no way of knowing whether my efforts were successful.

\section{Sabrina Thomas}

During the lockdown I felt isolated while working from home and homeschooling my children at our dining room table. The only thing that stayed "normal" was my social media access. Staying connected was vital; however, friends and acquaintances started to share conspiracy videos. Often, I was able to easily dispel misinformation that appeared on my timeline. But there were frustrating examples where my feedback was ignored or looked on with hostility. Enough bad experiences left me feeling burned out and fueling a budding existential crisis. If people are manipulated by misinformation regardless of the high-quality evidence I presented, then what is the point of teaching information literacy? I reached out to colleagues, who experienced similar things. Were other teaching librarians feeling burned out with the tsunami of COVID-19 misinformation? How did they avoid burnout? What were their best practices for commenting and dispelling misinformation? 


\section{COVID-19 MISINFORMATION _ COMMENTARY}

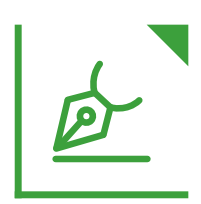

\section{Lindsey M. Harper}

The lockdown and work-from-home orders decreased my face-to-face interactions with people and increased my reliance on using virtual platforms to maintain connection with the world. Because of my increase in social media use, I realized just how much misinformation about COVID-19 was posted by my social media friends. At first, I worked tirelessly to combat this inaccurate information; doing this ultimately left me emotionally exhausted until I had to significantly reduce my exposure to these platforms.

\section{Introduction}

After learning from each of our own experiences as librarians during COVID-19, we realized we were not alone in our feelings of isolation, engaging with misinformation, and the subsequent burnout. Our definition of burnout comes from the Mayo Clinic (2018), "Job burnout is a special type of work-related stress-a state of physical or emotional exhaustion that also involves a sense of reduced accomplishment and loss of personal identity." We wanted to see whether a reduced sense of accomplishment and personal identity were prevalent themes among other librarian professionals, and if so, to what extent. A brief survey was created and distributed to assess librarians' experiences with misinformation and disinformation in their personal social media feeds during COVID-19, the impact of their professional life on their personal life and vice versa, and whether this leads to burnout among those surveyed.

After Marshall University's Institutional Review Board approved the developed survey, librarians were recruited via national library electronic discussion lists to gather a wide perspective from many different professional librarians. This survey was distributed online via Qualtrics between June 25 and July 24, 2020. The initial emails were sent to two discussion lists on June 24, with additional emails sent on July 8 and July 15 for one of the two discussion lists, respectively.

Librarians $(N=94)$ from primarily academic $(75.53 \%)$ and health science (20.21\%) libraries composed the majority of those surveyed in this study. Among those surveyed, librarians are responsible for teaching information literacy as part of their professional job duties $(94.68 \%)$ and regularly participate in social media platforms (96.81\%). Further, $75.54 \%$ of those librarians indicated they frequently or sometimes use social media to access news sources about COVID-19.

\section{Initial Results}

From our results, librarians were more likely to engage with social media posts containing misinformation or disinformation about COVID-19 when the poster was a family member or friend; they were less likely to engage with

\section{JOIN THE}

Freedom to Read Foundation

\section{Become a member for only} $\$ 50$ per year.
unw.ftrf.org/Membership

(312) 280-4226 / Toll-free: (800) 545-2433 x4226

Freedom to Read Foundation

225 N. Michigan Avenue, 13th Floor, Chicago, IL 60611
Freedom to Read Foundation supporters:

- Help defend the First Amendment in the courts, including the U.S. Supreme

Court

- Support librarians and teachers around the country besieged by attempts to

- restrict library materials and services

- Participate in complimentary webinars

- Get bi-monthly email updates on censorship trends and FTRF actions/initiatives

- Connect with authors, librarians and teachers that support your work

- Vote for and are eligible to run for trustee positions in the annual board elections

\section{f freedomtoread $\boldsymbol{y} @ f t r f$}

Your support helps us accomplish these objectives:

- Have a stronger voice in the courts, within the library community, and in the

- public arena-more members and more resources mean greater visibility for the

- freedom to read

- Implement educational and legal initiatives and grants•Increase our organizational

capacity to ensure the continued vitality of the

- Freedom to Read Foundation for many years to come

\section{www.ftrf.org}




\section{COVID-19 MISINFORMATION _ COMMENTARY}

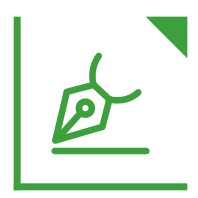

posts when the person was an acquaintance or lesserknown social media friend. When asked whether they have a responsibility to combat misinformation about COVID-19 in their personal lives, $71.28 \%$ indicated they "definitely should" or "probably should" do something about it. One librarian commented,

I don't try to completely change someone's opinion in a Facebook argument. I tend to focus on one aspect of their incorrect information and discuss reasonably and calmly and using noninflammatory language that connects with them to start dismantling their incorrect opinions.

Several librarians suggested speaking with the original poster one-on-one as a more effective way of combating misinformation and disinformation regarding COVID19. One librarian said, "Since leaving comments on posts doesn't seem to help, real conversations with people would seem the best approach," and another stated they did this by "messaging people privately instead of a public comment to save face, so people tend to respond better."

Librarians were asked whether they were feeling burned out from combating misinformation and disinformation about COVID-19 on social media; 69.15\% of our surveyed librarians indicated feelings of burnout "frequently" or "some of the time." One librarian stated,

\footnotetext{
One of the primary reasons I do not participate in social media is the burnout from trying to educate people, which happened prior to COVID-19. So my solution was to stop engaging in social media and only engage in direct dialogue with family and friends-where I still do need to combat misinformation, but it's less overwhelming.
}

\section{Discussion}

The results and comments presented from this study indicate the need for a wide-ranging discussion on best practices for information professionals to combat misinformation and disinformation, particularly as these issues extend beyond our professional lives and move into our personal spaces. The strategies developed for professional and personal approaches will likely differ yet overlap. The professional approach requires us to stay abreast of current issues and provide factual and evidence-based resources to combat misinformation; it requires us to remove our emotions from the equation. One librarian stated their best practice was to "keep everything completely factual and tone neutral." This approach certainly works when dealing with library users or people you do not know well. On the other hand, the personal approach requires a similar yet slightly different strategy, especially when it concerns relationships with whom we are personally vested. Another librarian stated that their best practice was, "not necessarily going in 'hard,' but instead acquiescing to that person's fear or worry and then sharing another perspective."

Setting both professional and personal boundaries to prevent burnout in this context is challenging because if there is not an army of people to combat misinformation, false information spreads rapidly - that is if our words are heeded online. Although information professionals are known for working in a "helping profession" and we will do so appropriately during work hours, it is important we not exhaust ourselves to the point of burnout via fighting battles of mis- and disinformation regarding COVID-19 in our personal lives that we may never win. One librarian in our survey said their best practice advice was to "choose your battles" and, until we develop better strategies to engage with these issues, find ways to disengage and maintain an appropriate work-life balance. In the interim, perhaps we will feel a bit less alone knowing we are all in this together.

The initial results and comments presented from this study will be explored more thoroughly in a future publication. Subsequent research will discuss burnout rates specifically and examine librarians' perceptions on the impact of their attempts to combat COVID-19 mis- and disinformation in their personal lives. Because of the nature and topic of the present study, we thought it was paramount to quickly explore a portion of these results with information professionals. This is especially true as it regards librarians' experiences combating COVID-19 content in what is truly the most unprecedented time for public health in more than a century.

\section{Reference}

Mayo Clinic Staff. 2018. "Job Burnout: How to Spot It and Take Action." November 21. https://www.mayoclinic .org/healthy-lifestyle/adult-health/in-depth/burnout /art-20046642. 